\title{
Thermal and Solvent-Resistant Properties of Organic-Inorganic Polymer Hybrids Having Interpenetrating Polymer Network Structure by Formation of Metal-Bipyridyl Complex
}

\author{
Tomoki OgOSHI, Hideaki ITOH, Kyung-Min KIM and Yoshiki CHUJO ${ }^{\dagger}$ \\ Department of Polymer Chemistry, Graduate School of Engineering, Kyoto University, \\ Yoshida, Sakyo-ku, Kyoto 606-8501, Japan
}

(Received September 26, 2002; Accepted December 18, 2002)

\begin{abstract}
Organic-inorganic polymer hybrids having IPN (Interpenetrating Polymer Network) structure were synthesized utilizing an in-situ method, which was the simultaneous formation of organic gel through metal-bipyridyl complex and silica gel. Metal-bipyridyl complex was used as a cross-linking point to prepare the organic gel. The properties of the polymer hybrids, such as solvent-resistant and thermal properties, were different according to the kinds and the weight of the used metal ions. Especially, thermo-responsive polymer hybrids could be obtained using iron (II)-bipyridyl complex as a cross-linking point in the silica matrix.

KEY WORDS Organic-Inorganic Polymer Hybrids / Sol-Gel Reaction / In-Situ Method / Interpenetrating Polymer Network (IPN) Structure / Solvent Resistant Property /
\end{abstract}

Organic-inorganic polymer nanocomposite materials have received a great amount of scientific and technological interests. ${ }^{1-5}$ Organic-inorganic polymer hybrids have not only the properties themselves of organic polymer and inorganic material but also the unique properties, which results from mixing of organic polymer and inorganic material at a nano-meter level. For instance, organic-inorganic polymer hybrids have high transparency, ${ }^{6}$ excellent solvent-resistance, ${ }^{7}$ gas-barrier property, flame retardance, gas-selective property, ${ }^{8}$ and so on. The sol-gel reaction of alkoxysilane is one of the most efficient methods for the preparation of organicinorganic polymer hybrids. The method comprises initial hydrolysis of the alkoxysilane and subsequent condensation and removal of solvent, resulting in the silica gel. ${ }^{9}$ One of the advantages of the sol-gel techniques to prepare composite materials is that the reactions can be performed under ambient condition, while conventional melt fusion technique for silica glass requires high temperature.

Organic-inorganic polymer hybrids have been prepared by utilizing the formation of covalent bonds between organic polymers and inorganic phases. ${ }^{10-12}$ In our group, a large variety of organic-inorganic polymer hybrids has been prepared through the sol-gel reaction of alkoxysilane. The most common method is utilizing physical interactions such as hydrogen bonding, ${ }^{13-15}$ aromatic, ${ }^{16}$ and ionic interactions ${ }^{17}$ between organic polymer and silica gel. Another method is an in-situ method, in which the polymerization of vinyl monomer and the sol-gel reaction of silica gel are carried out simultaneously. By utilizing this method, trans-

${ }^{\dagger}$ To whom correspondence should be addressed. parent polymer hybrids can be prepared even if there is no covalent or physical interaction between organic polymer and silica gel. For example, transparent polymer hybrids can be prepared by the simultaneous occurrence of the polymerization of styrene monomer and the formation of silica gel. ${ }^{18}$

Recently, we succeeded in the preparation of transparent polymer hybrids utilizing new in-situ method (Scheme 1). ${ }^{19}$ In this method, the cross-linking reaction of bipyridyl-containing polymer was carried out together with the sol-gel reaction of tetramethoxysilane in the presence of ruthenium salt. The obtained polymer hybrids using ruthenium-bipyridyl complex showed high thermal stability and excellent solventresistance. It was also found that the transparency of the polymer hybrids obtained was influenced by the rate of gelation of the organic polymer and the formation of silica gel. It means that the organic gel is entangled throughly with silica gel without any phase separation. The obtained polymer hybrids have an entangled combination of organic gel and silica gel, which is called a "complete-interpenetrating polymer network (complete-IPN)" structure. The complete-IPN structure has a unique structure, morphology, good dynamic property, and excellent solvent-resistant property compared with normal polymer blend system. It is feasible to prepare the polymer hybrids using responsive functional group as a cross-linking point. It is of great interest to investigate the dramatic change of some properties of polymer hybrids when some stimuli such as heat or light are introduced to the responsive function used as a cross-linking part. It is assumed that the changes of macrostructure caused by the change of microstructure 


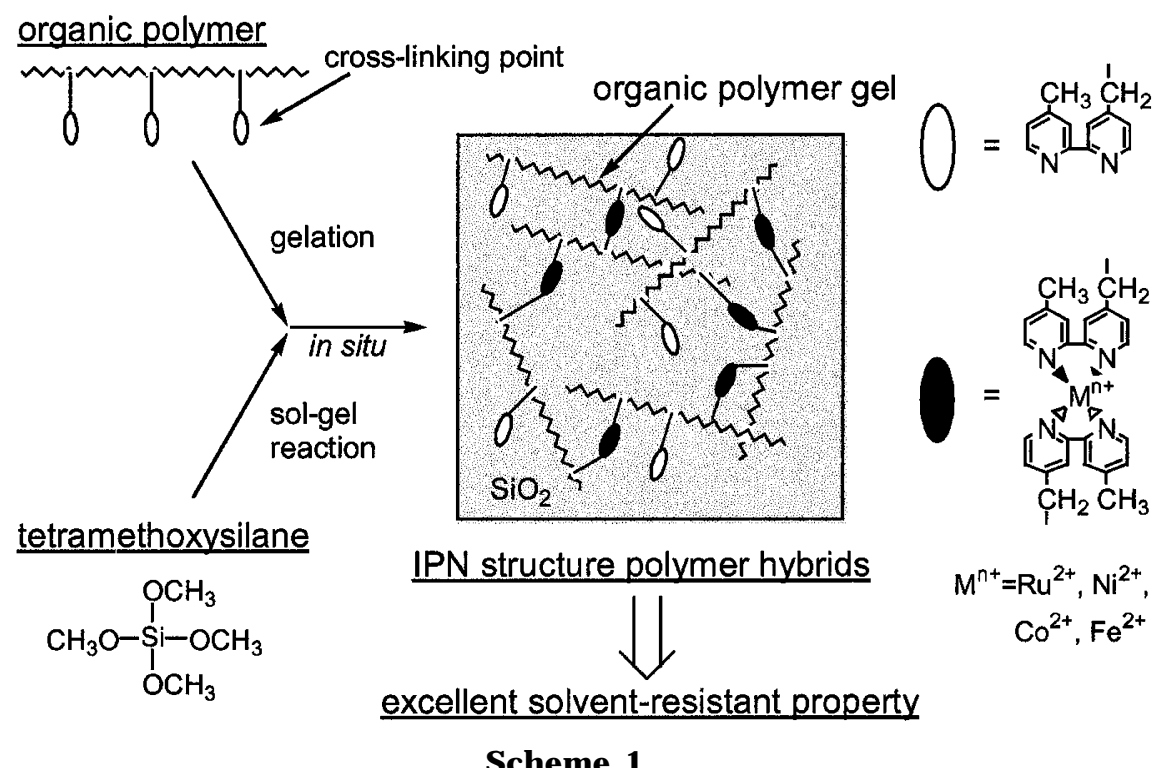

of cross-linking group, would affect the property of the polymer hybrids.

In this paper, four kinds of metal $\left(\mathrm{M}^{\mathrm{n}+}=\mathrm{Ru}^{2+}\right.$, $\left.\mathrm{Fe}^{2+}, \mathrm{Co}^{2+}, \mathrm{Ni}^{2+}\right)$ bipyridyl complexes ${ }^{20-22}$ were used as cross-linking points to prepare organic gel. It was known that $\mathrm{Ru}(\mathrm{II})$-bipyridyl and $\mathrm{Fe}(\mathrm{II})$-bipyridyl complexes were thermodynamically inert, while Fe(II)bipyridyl complex and Co(II)-bipyridyl complex were kinetically labile. It was found that the properties of polymer hybrids depended on the stability of organic gel prepared by the metal coordination. Thus, the properties of the organic gel in polymer hybrids should be dependent on both their thermodynamic stability constant and their kinetically inertness of metalbipyridyl complexes. Especially, Fe(II)-bipyridyl complex showed thermo-responsive property by thermal activation of the ligand exchange. ${ }^{21,22}$ The obtained polymer hybrids by utilizing Fe(II)-bipyridyl complex are also expected to show thermo-responsive property.

\section{EXPERIMENTAL}

\section{Materials}

All solvents and reagents were used as supplied except the following. Tetramethoxysilane (TMOS) was distilled and stored under nitrogen. Dimethylformamide (DMF) was dried and distilled over magnesium sulfate under reduced pressure and stored under nitrogen. Tetrahydrofuran (THF) was dried and distilled over sodium under nitrogen. Ethanol was dried and distilled from magnesium ethoxide.

\section{Measurements}

The ${ }^{1} \mathrm{H}$ NMR spectra were recorded on a $270 \mathrm{MHz}$ JEOL-JNM-GX270 NMR spectrometer. The UV-visi- ble diffuse reflectance spectra were measured with a Shimadzu model MPS-2000 multipurpose spectrometer. Thermogravimetric analysis (TGA) was performed using a TG/DTA6200, SEIKO Instruments, Inc., with heating rate of $10^{\circ} \mathrm{C} \mathrm{min}^{-1}$ in air. Scanning electron microscopy (SEM) measurements were conducted using a JEOL JNM-5310/LV system. The FT-IR spectra were obtained using a PerkinElmer 1600 infrared spectrometer. Nitrogen absorption porosimetry was conducted with a BEL JAPAN INC.

\section{Synthesis of Bipyridyl-Modified Polystyrene (BPY-PS)}

The synthetic route is shown in Scheme 2. Poly(styrene-co-vinylbenzyl chloride) (Cl-PS) was synthesized by radical polymerization. The bipyridyl group was quantitatively introduced to Cl-PS as described before. ${ }^{19}$ The substitution degrees of bipyridyl group were $10.8 \%$ and $10.6 \%$ determined from ${ }^{1} \mathrm{H}$ NMR and UV, respectively.

\section{Preparation of Organic-Inorganic Polymer Hybrids from $B P Y-P S$}

A DMF solution of BPY-PS was added to a mixture of TMOS, hydrochloric acid (0.1 M, 4eq to TMOS), and a DMF solution $(250 \mathrm{mg} / 25 \mathrm{~mL})$ of metal salts. The resulting mixture was stirred in a sealed bottle for a certain time before allowing the solvent to evaporate at $60^{\circ} \mathrm{C}$.

\section{Solvent-Resistant Property of Polymer Hybrids}

The powdered hybrids were put in cellulose timbers $(28 \mathrm{~mm} \times 100 \mathrm{~mm}$, Whatman Int., Ltd.) and extracted with chloroform, pyridine, and DMF. After extraction for 1 week, the samples were dried in a vacuum oven at $100^{\circ} \mathrm{C}$. 


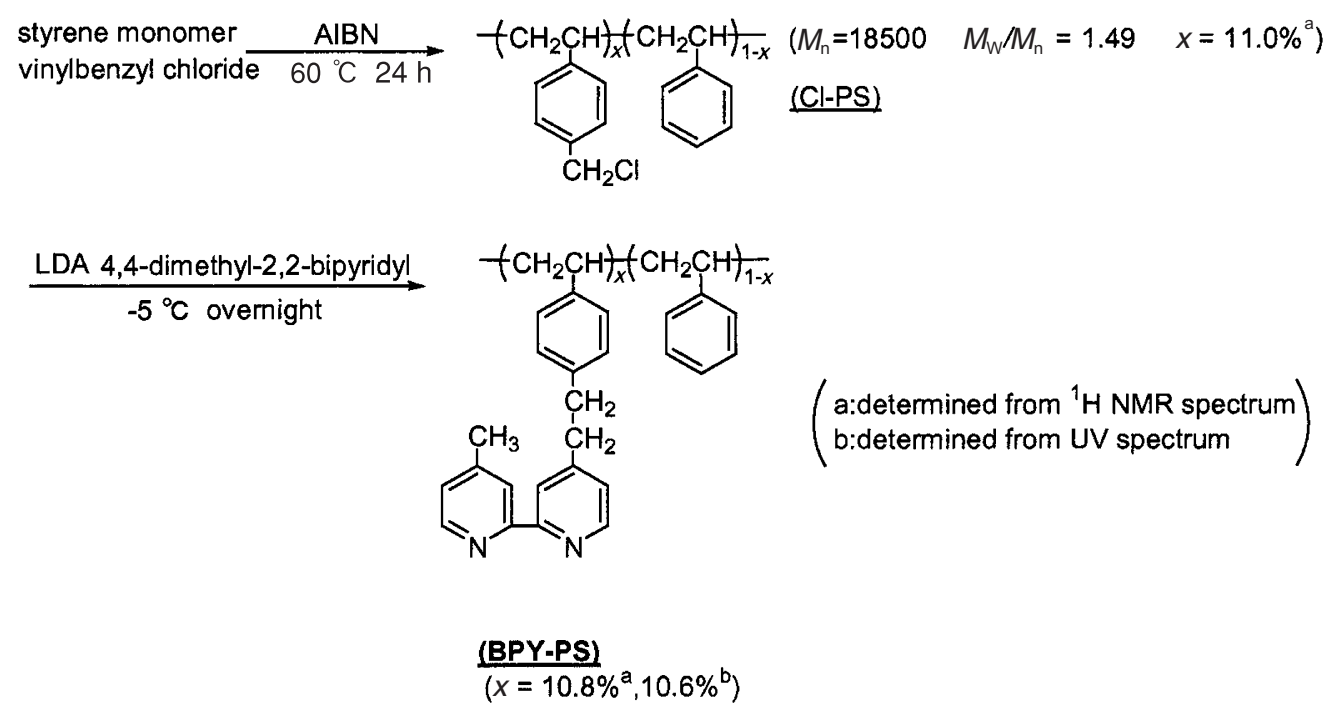

Scheme 2.

\section{Nitrogen Absorption Porosimetry}

The powder of polymer hybrids was heated at $600{ }^{\circ} \mathrm{C}$ in an ambient atmosphere for $24 \mathrm{~h}$ to remove organic components. The sample was dried at $200^{\circ} \mathrm{C}$ for $2 \mathrm{~h}$ at reduced pressure under nitrogen atmosphere before porosimetry measurements. The surface area was calculated with the Brunauer-Emmet-Teller (BET) equation in the range of 0.05 to $0.30\left(\mathrm{p} / \mathrm{p}_{0}\right)$ and the pore size distribution was calculated by the Barrett-JoynerHalenda (BJH) method.

\section{RESULTS AND DISCUSSION}

\section{Synthesis of Bipyridyl-Modified Polystyrene (BPY-PS)}

The bipyridyl-modified polystyrene (BPY-PS) was synthesized by the reaction of partially modified $\mathrm{Cl}$ PS with 4,4'-dimethyl-2,2'-bipyridyl in the presence of lithium diisopropylamide (LDA) (Scheme 2). ${ }^{19}$

The degree of chloromethyl group in partially modified Cl-PS was $11.0 \%$ determined by ${ }^{1} \mathrm{H}$ NMR, and the content of bipyridyl group in BPY-PS was $10.8 \%$ and $10.6 \%$ determined by ${ }^{1} \mathrm{H}$ NMR and UV, respectively. It means that the introduction efficiency of bipyridyl group was almost quantitative.

\section{Synthesis of Organic-Inorganic Polymer Hybrids by an In-Situ Method}

Organic-inorganic polymer hybrids were synthesized by an in-situ method. This method is not utilizing physical interaction such as hydrogen bonding, aromatic, ionic interactions between organic polymer and silica gel but utilizing the same rate of gelation of both organic polymer and silica matrix, which leads to an interpenetrating network of organic polymer gel and silica gel. The organic polymer gel through metal coordination was dispersed uniformly in the silica matrix at a nano-meter level. To prepare organic gel, four kinds of metals $\left(\mathrm{M}^{\mathrm{n}+}=\mathrm{Ru}^{3+}, \mathrm{Fe}^{2+}, \mathrm{Co}^{2+}, \mathrm{Ni}^{2+}\right)$-bipyridyl complexes were used as cross-linking points. IPN structure of BPY-PS gel and silica gel was constructed by an in-situ method (Table I). Homogeneous and transparent polymer hybrids were obtained by controlling the stirring time and the addition time of metal salt. In case of using ruthenium and iron salts, transparent polymer hybrids could be obtained in lower polymer ratio (runs 1,2 , and 7), but higher polymer ratio brought about the translucent films (runs 3 and 8). Transparent polymer hybrids using cobalt and nickel salts could be easily prepared in a wide range regardless of the polymer ratio (run 4-6, run 9-11).

These results indicate that ruthenium(II) and iron(II) complexes are known to be thermodynamically so inert that the intermolecular polymer networks are easily formed even in the low concentration (Scheme 3, Path I). On the other hand, cobalt(II) and nickel(II) complexes are labile, which cause the intramolecular polymer network in the low concentration. As the solvent was gradually evaporated, the concentration of the solution became high. This means that the first formed intramolecular cross-linking networks shift to intermolecular cross-linking networks (Scheme 3, Path II). This can be explained by high dilution accelerate ligand exchange reaction. Generally, the rate of ligand exchange is in the following order; $\mathrm{Ni}^{2+}>\mathrm{Co}^{2+}$ $>>\mathrm{Fe}^{2+}>\mathrm{Ru}^{2+} .{ }^{23}$ Thus, it is concluded that using cobalt(II) and nickel(II) complexes, the simultaneous formation of the organic polymer network and silica gel takes place much more easily than using ruthenium(II) and iron(II) complexes, so transparent polymer hybrids could be obtained even in high polymer ratio without any difficulties. To prevent from evaporating of TMOS, polymer hybrids were prepared and covered with alu- 
Table I. Synthesis of organic-inorganic polymer hybrids using BPY-PS ${ }^{\mathrm{a}}$

\begin{tabular}{ccccccc}
\hline run & metal & $\begin{array}{c}\text { BPY-PS } \\
(\mathrm{mg})\end{array}$ & $\begin{array}{c}\text { TMOS } \\
(\mathrm{mg})\end{array}$ & appearance & \multicolumn{2}{c}{ polymer content (wt\%) } \\
\cline { 5 - 7 } & & 50 & 500 & transparent & 19.8 & obsd. $^{\mathrm{y}}$ \\
\hline 1 & $\mathrm{RuCl}_{3}$ & 50.6 \\
2 & $\mathrm{RuCl}_{3}$ & 100 & 500 & transparent & 33.1 & 40.0 \\
3 & $\mathrm{RuCl}_{3}$ & 100 & 250 & translucent & - & - \\
4 & $\mathrm{CoCl}_{2}$ & 50 & 500 & transparent & 20.0 & 28.6 \\
5 & $\mathrm{CoCl}_{2}$ & 50 & 250 & transparent & 32.9 & 47.7 \\
6 & $\mathrm{CoCl}_{2}$ & 50 & 125 & transparent & 49.0 & 61.6 \\
7 & $\mathrm{FeSO}_{4}$ & 50 & 250 & transparent & 32.9 & 44.3 \\
8 & $\mathrm{FeSO}_{4}$ & 50 & 125 & translucent & - & - \\
9 & $\mathrm{NiCl}_{2}$ & 50 & 250 & transparent & 32.9 & 47.2 \\
10 & $\mathrm{NiCl}_{2}$ & 50 & 125 & transparent & 49.0 & 53.6 \\
11 & $\mathrm{NiCl}_{2}$ & 50 & 62.5 & transparent & 64.9 & 68.1 \\
\hline
\end{tabular}

${ }^{\mathrm{a}} \mathrm{DMF} 5 \mathrm{~mL}$, metal $2 \mathrm{mg}, \mathrm{HCl}_{\mathrm{aq}}(0.1 \mathrm{M})$ 4eq to TMOS, DMF was evaporated at $60^{\circ} \mathrm{C}$. ${ }^{\mathrm{b}}$ Determined by TGA.
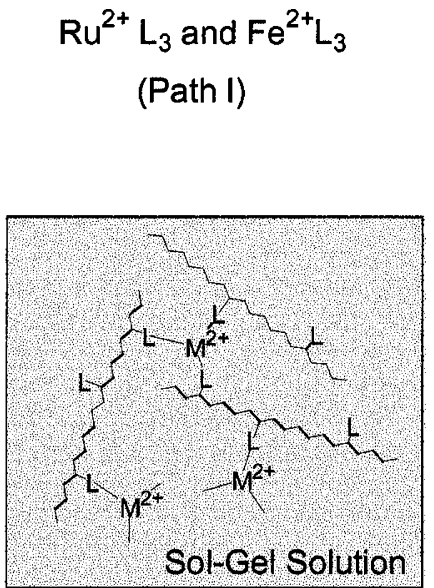

intermolecular polymer network
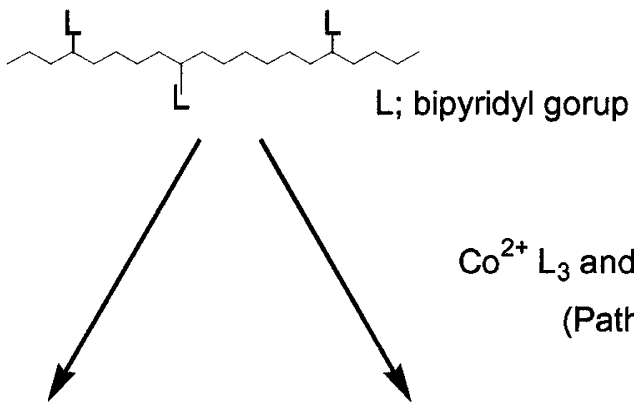

$$
\mathrm{Co}^{2+} \mathrm{L}_{3} \text { and } \mathrm{Ni}^{2+} \mathrm{L}_{3}
$$

(Path II)
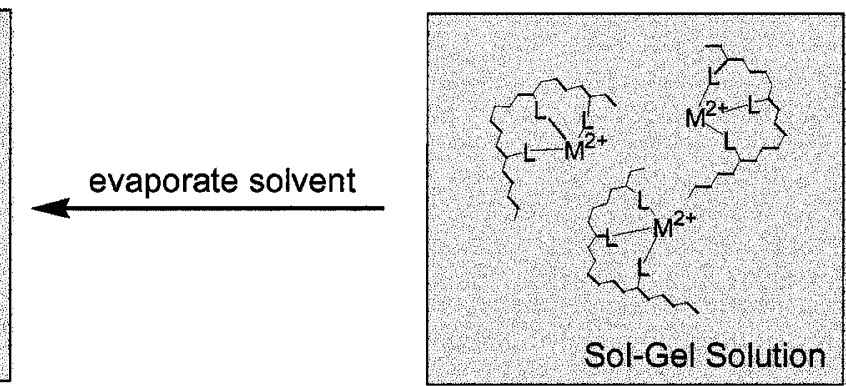

intramolecular polymer network

Scheme 3.

minum foil a few pinholes and heated in air at $60^{\circ} \mathrm{C}$, but a little TMOS was evaporated before gelation of TMOS. So organic polymer contents by TGA were different from calculated values.

\section{The UV Spectra of Polymer Hybrids}

When metal salt was put in the DMF solution of BPY-PS, the solution color was changed (Table II).

It is considered that the metal-bipyridyl complex was formed in DMF solution. In case of using rutheniumbipyridyl complex, the color of polymer hybrids was violet-black, and the characteristic absorption peak appeared around $480 \mathrm{~nm}$ in the solid UV spectrum. The color of polymer hybrids utilizing iron-bipyridyl complex was red, and the absorption peak also appeared around $500 \mathrm{~nm}$. These absorption bands can be as-
Table II. Color change by adding metal salt

\begin{tabular}{cllc}
\hline run & metal salt (color) & $\begin{array}{l}\text { color after } \\
\text { adding metal }\end{array}$ & $\begin{array}{c}\lambda_{\max }{ }^{\mathrm{a}} \\
\mathrm{nm}\end{array}$ \\
\hline 12 & $\mathrm{RuCl}_{3}$ (black) & violet-black & 480 \\
13 & $\mathrm{FeSO}_{4}$ (brown) & red & 500 \\
14 & $\mathrm{CoCl}_{2}$ (deep blue) & orange-yellow & - \\
15 & $\mathrm{NiCl}_{2}$ (green) & colorless & - \\
\hline
\end{tabular}

${ }^{\mathrm{a}}$ Measured by UV-visible diffuse reflectance spectra.

signed to a metal-to-ligand charge transfer (MLCT) absorption. It is considered that the organic polymer is cross-linked by the formation of the metal-bipyridyl complex in the silica matrix. In case of cobalt(II) and nickel(II) ions, the characteristic absorption peak was not observed in the solid state UV spectra. Unfortunately, the sensitivity of UV-visible diffuse reflectance 


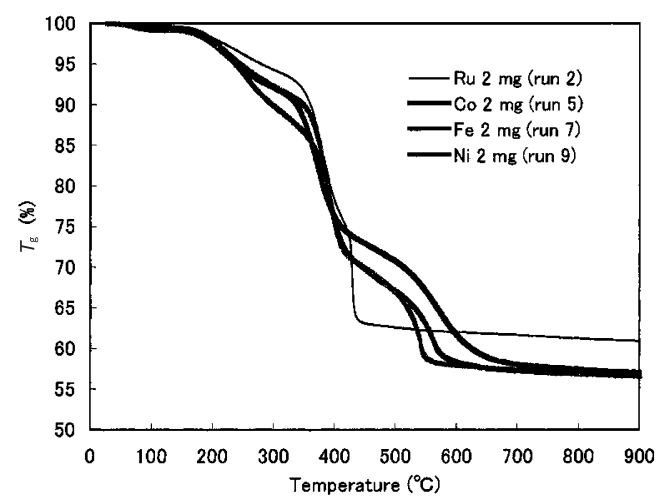

Figure 1. TGA analysis of polymer hybrids in air utilizing four kinds of metal-bipyridyl complexes.

spectra (solid UV spectra) was low around $300 \mathrm{~nm}$, so MLCT peaks of cobalt(II)-bipyridyl and nickel(II)bipyridyl cannot be measured precisely. But the color of polymer hybrids was light yellow and colorless utilizing cobalt(II)-bipyridyl complex and nickel(II)bipyridyl complex, respectively. It is thought that the metal-bipyridyl complexes using cobalt(II) and nickel(II) ions are also formed in the silica matrix.

\section{Thermal Property of Polymer Hybrids}

TGA study of the obtained polymer hybrids is shown in Figure 1.

In run 2 (utilizing ruthenium(II)-bipyridyl complex), $T_{10}$ was $357^{\circ} \mathrm{C}$, in run 5 (utilizing cobalt(II)bipyridyl complex), $T_{10}$ was $295^{\circ} \mathrm{C}$, in run 7 (utilizing iron(II)-bipyridyl complex), $T_{10}$ was $337^{\circ} \mathrm{C}$, and in run 9 (utilizing nickel(II)-bipyridyl complex), $T_{10}$ was $348^{\circ} \mathrm{C}$. These results can be explained by the strength of metal-ligand formation. That is, the strength of ruthenium(II)-bipyridyl complex is strongest among those of the other metal-bipyridyl complexes, which shows the highest thermal stability. But, unexpectedly, the thermal stability of iron(II)-bipyridyl complex was lower than that of nickel(II)-bipyridyl complex even if the thermodynamic stability of iron complex was stronger than that of nickel(II) complex. It might be resulted from kinetic unstability of iron(II)-bipyridyl complex, whose property will be discussed in the following. Some unclear points about TGA analysis still remained, but it is possible to mention that the difference of thermal stability depends on the coordination ability of metal-bipyridyl complexes.

\section{Solvent-Resistant Property of Polymer Hybrids}

The solvent-resistant property by the formation of IPN polymer hybrids was estimated by means of solvent extraction experiments. The obtained polymer hybrids were crushed into powders, which were extracted with $\mathrm{CHCl}_{3}$ and pyridine. The results are shown in Ta-
Table III. Solvent extraction efficiency ${ }^{\mathrm{a}}$

\begin{tabular}{cccc}
\hline \multirow{2}{*}{ run } & \multirow{2}{*}{ metal } & \multicolumn{2}{c}{ solvent extraction efficiency (\%) } \\
\cline { 3 - 4 } & & $\mathrm{CHCl}_{3}$ & pyridine \\
\hline 2 & $\mathrm{RuCl}_{3}$ & 0.41 & 9.62 \\
5 & $\mathrm{CoCl}_{2}$ & 15.5 & 20.1 \\
7 & $\mathrm{FeSO}_{4}$ & 4.40 & 32.5 \\
9 & $\mathrm{NiCl}_{2}$ & 28.5 & 13.2 \\
\hline
\end{tabular}

${ }^{\mathrm{a}}$ The polymer content of the polymer hybrids before $\left(p_{\mathrm{b}}\right)$ and after $\left(p_{\mathrm{a}}\right)$ the extraction was calculated from TGA in air, and the solvent extraction efficiency $\mathbf{E}$ was calculated according to the equation : $\mathbf{E}=100\left(p_{\mathrm{b}}-p_{\mathrm{a}}\right) / p_{\mathrm{b}}\left(100-p_{\mathrm{a}}\right)$.

ble III.

The high amounts of the extraction of organic polymer in polymer hybrids mean that the solvent-resistant property is low. When $\mathrm{CHCl}_{3}$ was used as a solvent, the solvent-resistant property of the polymer hybrids was decreased in the following order; $\mathrm{Ru}(\mathrm{II})$ $>\mathrm{Fe}(\mathrm{II})>>\mathrm{Co}$ (II) $>\mathrm{Ni}$ (II). These differences are mainly resulted from the constant of coordination ability between bipyridyl-modified polymer and metal ions. The thermodynamic coordination constant of metalbipyridyl is decreased in the following order; ${ }^{22} \mathrm{Ru}(\mathrm{II})$ $>>\mathrm{Fe}$ (II) $>>\mathrm{Co}$ (II) > Ni (II). However, in case of using pyridine as a solvent, the solvent-resistant property of the polymer hybrids is decreased in the following order; $\mathrm{Ru}$ (II) $>>\mathrm{Ni}$ (II) $>\mathrm{Co}$ (II) $>\mathrm{Fe}$ (II). The polymer hybrids utilizing ruthenium(II)-bipyridyl complex showed the most excellent solvent-resistant property in both $\mathrm{CHCl}_{3}$ and pyridine solvents. When pyridine was used as a solvent compared with $\mathrm{CHCl}_{3}$, the solvent-resistant property of the polymer hybrids utilizing iron(II) and cobalt(II) ions was more decreased than that of polymer hybrids utilizing Ni(II). This result means that iron(II)-bipyridyl and cobalt(II)-bipyridyl complexes have a kinetically labile property. Thus, pyridine can coordinate iron(II) or cobalt(II) more easily than ruthenium(II) or nickel(II). It leads to the decrease of cross-linking points between organic polymers. In other words, the cross-linking point of the organic gel utilizing iron(II) or cobalt(II) was destroyed and then extracted.

Thermal Responsive Property of Polymer Hybrids Utilizing Iron-Bipyridyl Complex as a Cross-Linking Point

Among various metal salts used, iron(II)-bipyridyl complex gel, the medium inert complex gel, was found to have unique property such as ligand exchange reaction caused by thermal activation. Increasing of the temperature, the ligand exchange reaction was taking place more easily than other metal-bipyridyl complexes. The effect of temperature on solvent extraction of polymer hybrids is shown in Figure 2.

When extraction temperature became high, the sol- 


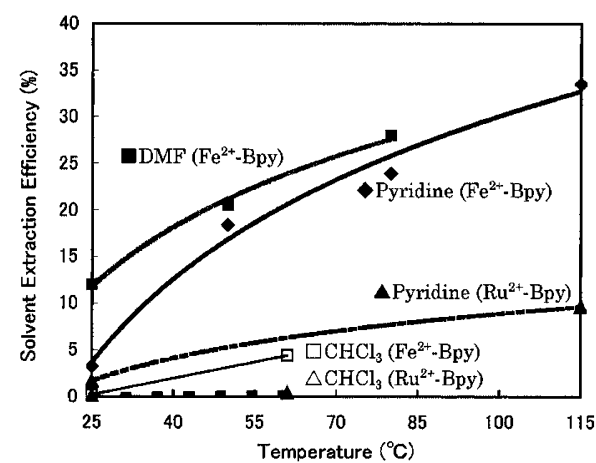

Figure 2. Effect of temperature on solvent extraction of polymer hybrids ( $\cdots$ DMF Fe(II)-Bpy: Table I, run $7, \diamond \cdots$ pyridine Fe(II)-Bpy: Table I, run 7, $\mathbf{\Delta} \cdots$ pyridine $\mathrm{Ru}(\mathrm{II})$-Bpy: Table I, run 2, $\square \cdots \mathrm{CHCl}_{3} \mathrm{Fe}(\mathrm{II})$-Bpy: Table I, run 7, $\triangle \cdots \mathrm{CHCl}_{3} \mathrm{Ru}(\mathrm{II})$-Bpy: Table I, run 2).

vent extraction efficiency using DMF or pyridine as a solvent was drastically increased. Thermal response of the polymer hybrids by utilizing iron(II)-bipyridyl complex was higher than that of the polymer hybrids utilizing ruthenium(II)-bipyridyl complex. On the other hand, the solvent extraction efficiency using $\mathrm{CHCl}_{3}$ as a solvent was not increased even at high temperature. It is considered that pyridine and DMF have enough coordination ability to form metal complex. At high temperature, iron(II)-bipyridyl complex can be changed to iron(II)-pyridine or iron(II)-DMF complex. Therefore, iron(II) ion can be easily extracted by pyridine and DMF, which means the decrease of cross-linking points between organic polymers, and the organic polymer is thus extracted. But in case of using $\mathrm{CHCl}_{3}, \mathrm{CHCl}_{3}$ can not coordinate iron(II) ion, that is, iron(II)-bipyridyl complex is not destroyed, so the cross-linking points are not decreased. As a result, the solvent extraction efficiency utilizing $\mathrm{CHCl}_{3}$ as a solvent is not increased even at high temperature.

\section{Effect of Cross-Linking Points on Solvent Extraction of Polymer Hybrids}

For the elucidation of IPN structure of the polymer hybrids, the solvent extraction experiment was carried out according to the weight of metal ions. It is expected that the extraction of organic polymer would be prevented if the cross-linking points were increased. To increase cross-linking points between organic polymers, the weight of ruthenium salt was increased. The results are shown in Figure 3.

As the weight of ruthenium salt was increased, the extraction efficiency of organic polymer was decreased using $\mathrm{CHCl}_{3}$ as an extraction solvent. It means that the solvent-resistant property is improved. On the other hand, in case of using pyridine, the extraction efficiency of organic polymer was not de-

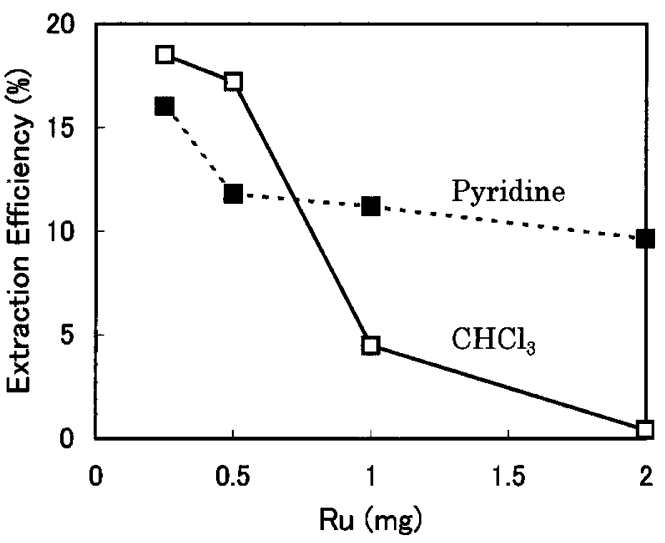

Figure 3. Effect of cross-linking point on solvent extraction of polymer hybrids (organic/inorganic $=1 / 2$, utilizing ruthenium(II)bipyridyl complex).

creased even if the weight of ruthenium salt was increased. It is confirmed that pyridine can coordinate ruthenium(II) ion, which accelerates ligand exchange reaction from ruthenium(II)-bipyridyl complex to ruthenium(II)-pyridine complex. Ruthenium(II)pyridine complexes were extracted, and the crosslinking points between organic polymers were decreased. Then the organic polymer in polymer hybrids was extracted by pyridine.

\section{Nitrogen Absorption Porosimetry Study}

The homogeneous polymer hybrids were investigated quantitatively by measuring pore size of porous silica obtained by charring the BPY-PS/Silica hybrids at $600^{\circ} \mathrm{C}$ in an ambient atmosphere for $24 \mathrm{~h}$ (Figure 4).

The organic parts would be removed from polymer hybrids by sintering the hybrids at $600^{\circ} \mathrm{C}$. The siloxane lattice is so rigid that it would not be affected at this temperature. Therefore, the size of the remained pores is expected to be comparable to the size of the domain of organic polymer. A surface area and a pore volume were calculated by the BET method and a pore size was determined by BJH method.

As shown in Table IV, the porous silica obtained from homogeneous polymer hybrids (Table I, run 5, utilizing cobalt salt) was found to have a quite large surface area and a pore volume. It was also observed that the porous silica had a sharp pore size distribution at $1.7 \mathrm{~nm}$ (Figure 5). This result showed the presence of nano-pores in the silica matrix. Because the pore size might be the domain of BPY-PS in the polymer hybrids, it is thought that BPY-PS is dispersed at a nano-meter level in the silica matrix. Furthermore, the obtained porous silica also contained metal ion at a nano-level in the silica, so the porous silica can be expected to apply a high efficient catalyst for gas or liquid reaction. This porous silica with metal ion is also one of the promising candi- 


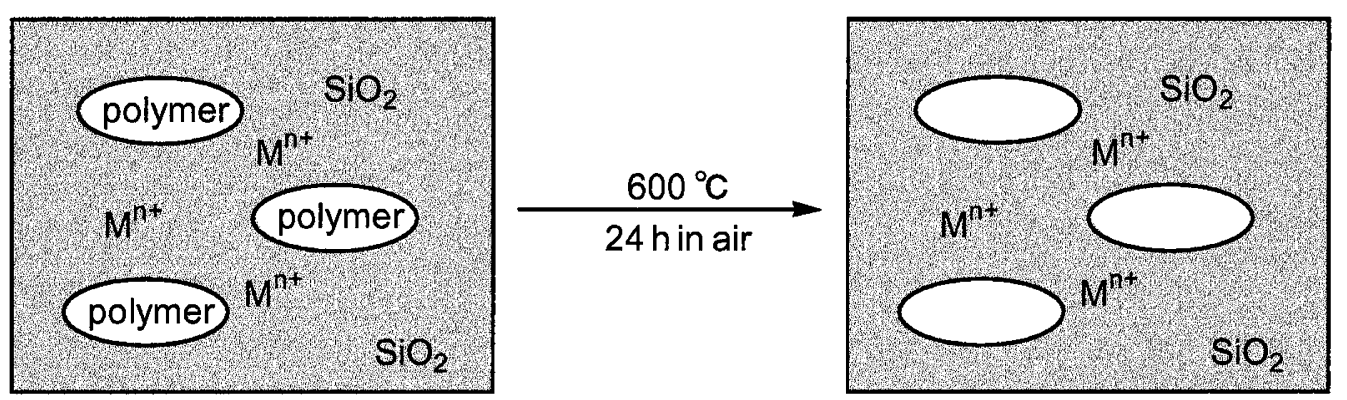

Figure 4. Formation of porous silica from the polymer hybrid.

Table IV. Porosity of the silica obtained from BPY-PS/silica hybrids

\begin{tabular}{cccc}
\hline run & $\begin{array}{c}\text { pore volume }^{\mathrm{a}} \\
\left(\mathrm{mL} \mathrm{g}^{-1}\right)\end{array}$ & $\begin{array}{c}\text { surface area }^{\mathrm{a}} \\
\left(\mathrm{m}^{2} \mathrm{~g}^{-1}\right)\end{array}$ & $\begin{array}{c}\text { pore radius }^{\mathrm{b}} \\
(\mathrm{nm})\end{array}$ \\
\hline 5 & 99.5 & 433.1 & 1.7 \\
\hline
\end{tabular}

${ }^{\mathrm{a}}$ Calculated by BET. ${ }^{\mathrm{b}}$ Calculated by BJH method.

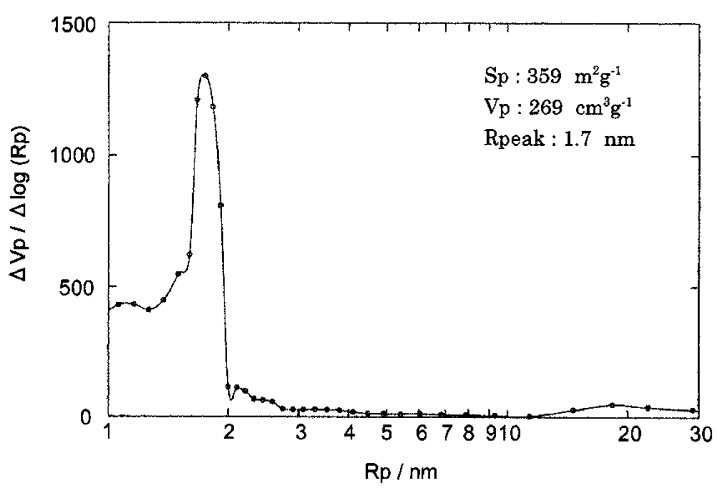

Figure 5. Pore size distribution plots of porous silica obtained from polymer hybrids (Table I. run 5).

dates for in-printing materials in the field of materials science.

\section{CONCLUSIONS}

Transparent and homogeneous IPN polymer hybrids could be obtained by utilizing four kinds of metalbipyridyl complex as cross-linking points in the silica matrix. The obtained polymer hybrids showed different properties depending on the kinds of metal-bipyridyl complexes. The polymer hybrids by utilizing iron(II)bipyridyl complex had a thermo-responsive property. The obtained porous silica from polymer hybrids had nano-pores. It is considered that the organic polymer was dispersed at nano-meter level in the silica matrix. And the obtained porous silica contained metal ion at nano-level. The porous silica would be used as an excellent efficient catalyst for the heterogeneous organic reactions.

\section{REFERENCES}

1. B. M. Novak, Adv. Mater, 5, 442 (1993).

2. U. Schubert, N. Hüsing, and A. Lorenz, Chem. Mater., 7, 2010 (1995).

3. P. Judeinstein and C. Sanchez, J. Mater. Chem., 6, 511 (1996).

4. J. Wei and G. L. Wilkes, Chem. Mater, 8, 1667 (1996).

5. Y. Chujo, Curr. Opin. Solid State Mater. Eng., 1, 806 (1996).

6. C. F. Bohren and D. R. Huffman, "Absorption and Scattering of Light by Small Particles,” Wiley, New York, N.Y., 1983, p 3.

7. Y. Chujo, S. Kure, H. Matsuki, T. Saegusa, and T. Yazawa, Polym. Prep. Jpn., 42, 839 (1993).

8. R. Tamaki, Y. Chujo, K. Kuraoka, and T. Yazawa, J. Mater. Chem., 8, 1741 (1999).

9. C. J. Brinker and G. W. Scherer, "Sol-Gel Science, The Physics and Chemistry of Sol-Gel Processing," Academic Press Inc., San Diego, CA, 1990, p 97.

10. H.-H. Huang, B. Orler, and G. L. Wilkes, Macromolecules, 20, 1322 (1987).

11. Y. Wei, D. Yang, L. Tang, and M. K. Hutchins, J. Mater. Res., 8, 1143 (1993).

12. Y. Wei, J.-M. Yeh, X. Jia, and J. Wang, Chem. Mater., 7, 969 (1995).

13. Y. Chujo and T. Saegusa, Adv. Polym. Sci., 100, 11 (1992).

14. T. Saegusa and Y. Chujo, Makromol. Chem., Macromol. Symp., 51, 1 (1991).

15. Y. Chujo, H. Matsuki, S. Kure, T. Saegusa, and T. Yazawa, $J$. Chem. Soc., Chem. Commun., 635 (1994).

16. R. Tamaki, K. Samura, and Y. Chujo, Chem. Commun., 1131 (1998).

17. R. Tamaki and Y. Chujo, Chem. Mater., 7, 1719 (1999).

18. R. Tamaki, K. Naka, and Y. Chujo, Polym. Bull., 39, 303 (1997).

19. T. Ogoshi, H. Itoh, K. M. Kim, and Y. Chujo, Macromolecules, 35, 334 (2002).

20. M. Schröder and T. A. Stephenson, "Comprehensive Coordination Chemistry", G. Wilkinson, Ed., Pergamon Press, New York, N.Y., 1987, vol. 4, p 215.

21. F. Basolo, J. C. Hayes, and H. M. Neumann, J. Am. Chem. Soc., 75, 5102 (1953).

22. F. Basolo, J. C. Hayes, and H. M. Neumann, J. Am. Chem. Soc., 76, 3807 (1954).

23. Y. Chujo, K. Sada, and T. Saegusa, Macromolecules, 24, 6315 (1993). 